\title{
Optimization of solar source based network
}

\author{
Fergani. $S^{1}$, Si ali. $\mathrm{M}^{2}$,Flazi. $\mathrm{S}^{3}$ and Boudghene Stambouli. $\mathrm{A}^{4}$ \\ ${ }^{1,2,3}$ Department of electrical engineering,e-mail: \\ fergani.samia@hotmail.fr,m.siali.teme2@hotmail.fr,flazis@yahoo.fr \\ ${ }^{4}$ Department of electronics, e-mail: stambouli@ssb-foundation.com \\ University of sciences and the Technology of Oran Mohamed Boudiaf
}

\begin{abstract}
This paper shows the importance of the electric cables sections and the site of renewable energy generator in order to optimize its distribution network. These parameters influence considerably the whole cost of installation during the running of a project. An approach of resolution consists of determining the position of installing the generator. This position is called electric center of gravity 'E.C.G in which the generator is then placed between various loads. This proposed position is known as having minimum of copper volume, that mean the least price of cable for the complete installation. The determined cross sections for each cable, in this position, are the smallest technically acceptable. An optimal section has been calculated in order to achieve the lowest annual cost of the investment. The obtained results prove that the adoption of this section has an effective economical profit in terms of energy gain.
\end{abstract}

\section{Key words}

Optimization, solar generator, distribution network, choice of section.

\section{Introduction}

The solar photovoltaic (PV), which is the direct conversion of sunlight into electricity, using solar cells, represents an attractive and well suited mean to produce energy [1]. In spite of its simplicity of implementation, its weak environmental impact and the low maintenance which it requires, a PV system is not competing any more when energy request increases, thus a rigorous study is necessary to make the best choice with the lowest possible costs [2].

The optimization of solar source based network is composed of two parts: the first is solar generators optimization, and the second is grid topology optimization. In our present work we are interested by the second part only.

The production of electrical energy from renewable energy sources in tertiary zone (tertiary zone covers a large activity numbers: trade, administration, transport, financial, real estate activities, business and personal services, education, health and social action. This sector is complimentary to the agricultural and industrial activities (primary and secondary sector)) is generally not of great quantity; a loss of power in its distribution network will involve an additional cost to the production which implies a considerable increase in the number of PV modules to be used, and thus an increase in the cost price of the production power station and an increase in the invoicing of electrical energy, so it becomes imperative to reduce the line losses [3].

In addition, knowing that the cross sections of the electrical cables have an impact on the energy losses, they also play a role in the choice of distributions networks to be designed and installed.

The objective of our work consists of optimizing the quantity of copper, and the heat losses of the electrical cables connected to a solar generator to decrease the maximum adjusted overall cost on the lifespan of the cable; therefore it is important to determine where we should place the renewable energy based generator.

\section{The electric center of gravity (E.C.G)}

As from the moment when it is possible to implement solar collectors on a site, the choice of PV generator is essential, in order to create a suitable architecture of a distribution network, so it is important to be able to optimize the position of these generators.

The position determination of installing the generator, for a constant voltage drop, is achieved by the technique of the gravity center, which allows obtaining an optimal topology between the loads and the solar generator corresponding to a volume of the most optimal copper for cables used, and thus a fixed price minimized. The method used is a determination of the gravity center of a system consisting of electric loads (motors, buildings...) represented by points of various powers, as shown in figure 1 . 
We are assuming that the sought center is at point E.C.G $\left(X_{0}, Y_{0}, Z_{0}\right)$, we will then, have the following coordinates, according to the study in our group, which may be presented in the same conference.

$$
\begin{aligned}
X_{0} & =\frac{\sum_{i=1}^{n} X_{i} \times P_{i}}{\sum P_{i}} \\
Y_{0} & =\frac{\sum_{i=1}^{n} Y_{i} \times P_{i}}{\sum P_{i}} \\
Z_{O} & =\frac{\sum_{i=1}^{n} Z_{i} \times P_{i}}{\sum P_{i}}
\end{aligned}
$$

Where $\left(X_{i}, Y_{i}, Z_{i}\right)$ represent the position of $i^{\text {th }}$ charge in the site, and $\mathrm{n}$ the number of loads established on the site, $P$ represents the consumption by $i^{\text {th }}$ charge.

\section{A. Minimum volume and gravity center}

By placing the solar generator in the gravity center, the copper volume of electrical cables used to supply the various loads, corresponds to the minimum quantity, that is to say the sum of the product of cross sections and lengths of cables is minimum. If the solar generator is moved and the technical sections are calculated, the volume of copper becomes more important. In order to demonstrate announced precedent, a variation of the position of the solar generator starting from an origin $\left(\mathrm{X}_{0}=0, \mathrm{Y}_{0}=0\right)$ is necessary, thus using the Excel software calculator, we could check and confirm our results. The position of the solar generator for an optimization of the quantity of copper and fixed price of installation is therefore determined. This position can also correspond to the overall minimum cable lengths only if the cross sections are identical as chosen by [3], however, generally the technical sections of the electrical cables are not the same, because they are determined according to the powers and lengths of cables connected to the solar generator (shown below), it correspond to the smallest cross sections technically acceptable, therefore we can write:

$$
S_{i}=S_{\min }
$$

For a generator in the center of gravity:

For identical cross sections:

$$
\left(\sum_{i=1}^{n} L_{i} \times S_{i}\right)_{\min } \Rightarrow\left(\sum_{i=1}^{n} L_{i}\right)_{\min }
$$

$L_{i}$. Length of $\mathrm{i}^{\text {th }}$ electrical cable connecting the load to the solar generator.

$S_{i}$. Technical section of $\mathrm{i}^{\text {th }}$ electrical cable.

For not identical cross sections:

$$
\sum_{i=1}^{n} L_{i} \times S_{i}=\min \Rightarrow \sum_{i=1}^{n} L_{i} \neq \min
$$

For the electrical cables, the minimum cross sections are the smallest sections technically acceptable, and they correspond thus to the acceptable cables in which the resistances and losses are the highest.

Table I, shows the result of calculated sections and the cables lengths for the example of figure.1. In this example there are five different electrical loads, whose Cartesian coordinates, are starting from a selected known origin.

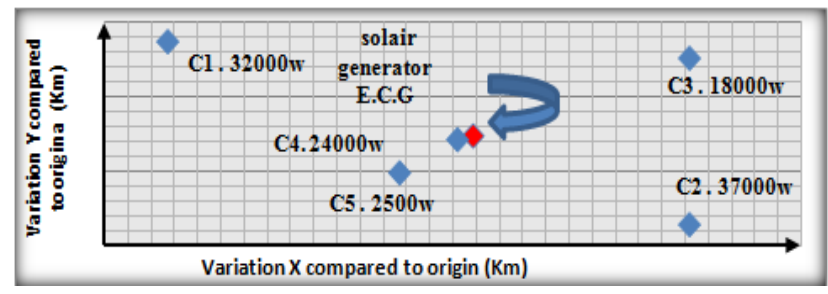

Fig. 1. Geographical positions of electrical loads and the generator of solar energy after application of the technique of the gravity center.

Knowing the position of electrical loads, and of solar generator, we can determine the length of the cables using the following formula:

$$
L=\sqrt{(X-X 0)^{2}-(Y-Y 0)^{2}}
$$

$X, Y$. Are coordinates of the loads.

For powers of known loads and considering that the voltage drop is constant; the determination of the technical section of each cable connected to the solar generator is then possible [4].

$$
S=\frac{\sqrt{3} \cdot I \cdot L \cdot 22,5 \cdot \operatorname{Cos}(\varphi)}{\Delta U}
$$

I. Current used, amp.

$\Delta U$. Voltage drop, volt.

In the formula 9 the cross section is given in $\mathrm{mm}^{2}$ and the length in $\mathrm{km}$.

Table I. - Calculates lengths and cross sections of electrical cables after optimization of solar generator position.

$\begin{array}{cccccccccc}P(W) & I(A) & X(K m) & Y(K m) & X 0(K m) & Y 0(K m) & \operatorname{COS}(\phi) & \Delta U(\mathrm{v}) & L(K m) & S\left(\mathrm{~mm}^{2}\right) \\ 32000 & 46,243 & 0,055 & 0,55 & 0,317 & 0,297 & 0,8 & 12 & 0,364 & 49,53 \\ 37000 & 53,468 & 0,505 & 0,055 & 0,317 & 0,297 & 0,8 & 12 & 0,306 & 47,912 \\ 18000 & 26,012 & 0,505 & 0,505 & 0,317 & 0,297 & 0,8 & 12 & 0,279 & 19,868 \\ 24000 & 34,682 & 0,305 & 0,285 & 0,317 & 0,297 & 0,8 & 12 & 0,017 & 1,612 \\ 25000 & 36,127 & 0,255 & 0,195 & 0,317 & 0,297 & 0,8 & 12 & 0,12 & 11,61\end{array}$

\section{B. Losses in the cables}

The cables used previously are designed with copper, a selected metal. 
Resistance $R$ of an electrical conductor is given by the formula (10) [5].

$$
R=\frac{\rho \times L}{S}
$$

Where $\rho$ represents the resistivity, $L$ the length and $\mathbf{S}$ the technical section.

In our site of 5 loads, with a solar generator placed at the center of gravity, the cross section of each cable is minimum; the resistance is then maximum as shown in the equation (10).

Thus, for a given intensity $I$, the heat losses $\left(R \times I^{2}\right)$ [6] are at their maximum, in contrast to [4], however the reduction of these losses is carried out by an increase in the cross section of the electrical cables, which can lead to optimize the exploitation cost. Indeed, by increasing the cross sections of electrical cables while keeping the position of the solar generator in the center of gravity, the cables resistance decreases, so the electric losses also decrease, whereas the quantity of copper will increase.

This observation allowed us to see an opposition between the exploitation cost and installation. An economic section must then be evaluated to decrease to the maximum the adjusted overall cost on the lifespan of the cable.

\section{Economic section and its calculation method}

The total cost evaluation of investment for the purchase, the installation of the cable and its use during the number of planned years of use is paramount. Indeed, the cable continues to cost money even after its installation and its utilization: its resistance permanently creates losses during its operation.

The economic section is a function of parameters (electrical energy cost, number of service hours ...) whose value varies during the period ( $\mathrm{N}$ years) that is considered for the amortization of installation, the variations of these values cannot be specified during the establishment of the project. The simplified calculates method that we present below, suppose that these parameters have a constant value during the considered period [7].

\section{A. Law of purchase price variation of the cable according to the section[7]}

We admit that the representation of the purchase price of the cable $P(\mathrm{DA} / \mathrm{km})$ according to the section $S\left(\mathrm{~mm}^{2}\right)$ is a straight line.

$$
\begin{gathered}
P=D+G S \\
\Rightarrow A P L=A(D+G S) L
\end{gathered}
$$

$\mathrm{D}$ and $\mathrm{G}$ are constants.

A. Annual amortization of the purchase price of the cable.

L. Length of electrical cable.

B. For an optimization of network with electrical source [7]

1) Amount of annual energy losses

$$
C=\operatorname{en} \rho \frac{L I^{2} H}{S} 10^{-3}
$$

C. Annual amount of the heat losses in the conductors, DA

e. Electrical energy price, DA/KWh

n. Active conductors number of the connection

$\rho$. Resistivity of the conductive metal at the service temperature, $\Omega \mathrm{mm}^{2} / \mathrm{Km}$

L. Length of the connection, $\mathrm{Km}$

I. Intensity to be transported, amps

H. Number of service hours of connection per year

S. Cross section of a conductor, $\mathrm{mm}^{2}$

2) Economic section, $\mathrm{Se}$

The total cost $C_{T}$ of Annual profitability of the purchase price, and annual amount of the energy losses has as an expression

$$
\begin{gathered}
C_{T}=A P L+C \\
C_{T}=A(D+G S) L+\frac{e n \rho H 10^{-3}}{S}
\end{gathered}
$$

It is the minimum for the section (Se) such as

$$
S_{e}=I \sqrt{\frac{e n \rho H 10^{-3}}{A G}}
$$

Practically the economic section is the closest of Se.

We have then determined the economic sections of each electrical cable connected to the energy distributor of "SONELGAZ" source leading to the lowest total annual cost according to the volume of copper and exploitation cost by the relation (16). 
Table II. - Economic sections calculate of the electrical cables from the technical cross sections.

$\begin{array}{cccccccccc}\text { e(DA/Kwh) } & \mathbf{n} & \boldsymbol{\rho}\left(\mathbf{\Omega} \mathbf{m m}^{\mathbf{2}} / \mathbf{K m}\right) & \mathbf{L}(\mathbf{K m}) & \mathbf{I}(\mathbf{A}) & \mathbf{H} & \mathbf{G} & \mathbf{A} & \mathbf{S}(\mathbf{m m}) & \mathbf{S e}\left(\mathbf{m m}^{\mathbf{2}}\right) \\ 4 & 3 & 22,5 & 0,365 & 46,243 & 4000 & 54117,647 & 0,237 & 49,530 & 13,419 \\ 4 & 3 & 22,5 & 0,306 & 53,468 & 4000 & 54117,647 & 0,237 & 47,912 & 15,515 \\ 4 & 3 & 22,5 & 0,280 & 26,012 & 4000 & 54117,647 & 0,237 & 19,868 & 7,548 \\ 4 & 3 & 22,5 & 0,018 & 34,682 & 4000 & 54117,647 & 0,237 & 1,612 & 10,064 \\ 4 & 3 & 22,5 & 0,120 & 36,127 & 4000 & 54117,647 & 0,237 & 11,610 & 10,483\end{array}$

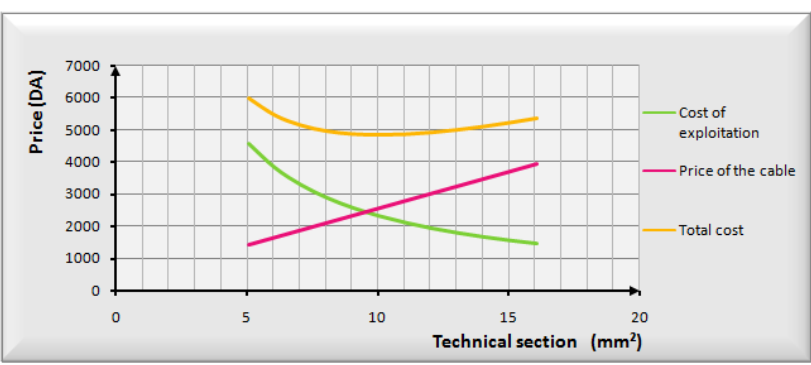

Fig. 2. The economic section graphical determination of a single electric charge (C4).

\section{3) Interpretation}

We showed in figure. 2 a graphical method for the determination of the economic section, for a single electric charge according to the volume of copper and the electric losses.

Knowing that the price of a cable is higher when the technical section of the conductors is stronger, then we will admit that the representation of the cable price according to the section is a right.

The increase of exploitation cost is interpreted by a considerable increase of the electrical energy invoicing [7], the reduction of these losses by joule effect according to the increase in cross section, represents an important profit of energy.

The sum of these two parameters determines the lowest annual cost (cable price and exploitation cost), so its minimum indicates the most economic section (Se).

\section{For an optimization of network with solar source}

- Solar generator price for energy losses

The annual price calculation (C2) of a solar generator according to the heat losses can be achieved by the following formula

$$
\begin{aligned}
& C_{2}=A \operatorname{Prn} \rho \frac{L I^{2} H}{S} 10^{-3} \\
& \rightarrow \operatorname{Pr}=F+J w \\
& \rightarrow J=\frac{P r_{1}-P r_{2}}{w_{1}-w_{2}}
\end{aligned}
$$

$$
\rightarrow w=n \rho \frac{L I^{2} H}{365 S h} 10^{-3}
$$

Pr. The fixed price of a solar generator, F and J. Are constant, w. Power required by the generator according to the heat losses $(\mathrm{kW})$, h. Represent the daily number of sunshine hours.

By graphical method used before (fig.2), we determined the economic sections for each cable connected to the solar generator, these sections are much larger compared to the economic sections of "SONALGAZ" source, considering that the $\mathrm{kWh}$ price is higher.

\section{4. $\quad$ Result}

The cross sections selected for the investment of our installation are the largest compared with the technical sections (S) and economic (Se), we called them the optimal sections. We could ask for a priori, why a larger cross section can lead ultimately to a lower cost. This is due to the fact that in certain cases, even if the cable is more expensive to purchase it is more economical to use, considering its reduced resistance (less losses), over several years of use, the price of the gained value on losses can compensate a larger initial investment [7].

In our case, to adopt the optimal sections, for an installation whose electrical cables are connected to a solar generator placed at the center of gravity, it is to make each year beyond amortization period, a considerable economy of the PV modules number to use, and thus a benefit of the cost price of the central production.

\section{Conclusion}

- The use of the electric gravity center technique allowed us to determine the energy generator position (electric or solar) in order that the copper volume of the cables used for an installation is the minimum, the smallest cross sections acceptable technically of each one of these cables are estimated in the same place, this influences considerably on the technical-economic evaluation of the installation (reduction of investment).

- In a context where the waste energy hunting becomes a duty, where each one should have the concern to facilitate the profitability of an investment, the consideration of the economic section is then the rule [7]. 
- The variation of power consumption by each load according to time periods affects instantaneously on the electric center of gravity and thus on the solar generator position, this will force us to recalculate all parameters that have a direct relation with economic section. This work will be the subject of our next study.

\section{References}

[1] Mohammed Elalami, Mohamed Habibi, Seddik Bri, "Parameters Efficiency of Solar Energy", International Journal of Emerging Trends in Engineering and Development, 2013, Vol. 4, Issue.3, pp. 175 - 186.

[2] Ould Mohamed Yahya, A. Ould Mahmoud et I. Youm, "Etude et Modélisation d'un Générateur Photovoltaïque", Revue des Energies Renouvelables, 2008, Vol. 11, N³, pp. $473-483$.
[3] R. Tchuidjan, O. Hamandjoda et M. Tabe, "Réduction des pertes de puissance dans un réseau de distribution alimenté par un générateur d'énergie nouvelle et renouvelable", Revue des Energies Renouvelables, 2011, Vol. 14, №3, $449-459$.

[4] Guide de l'ingénierie électrique des réseaux internes d'usines, ouvrage réalisé par un groupe animé par Gérard SOLIGNAC, ISBN 2-85206-311-5, deuxième tirage, revu juin 1986 , pp. $72-75$.

[5] Olivier Bourgeois, Hervé Guillou "Conduction électrique dans le solides-Introduction et théories élémentaires", techniques de l'ingénieur, 2013, référence d2601, 7200092269, pp.8

[6] Mathias Laffont, "perte d'énergie dans les réseaux de distributions d'électricité', juin 2009. [mathiaslaffont.files.wordpress.com/2011/01/rdv-tel27_04_091.pdf]

[7] Guide "câbles est files électriques-appareillage" tréfiméteaux, division appareillage .montage, 14 Edition 1977, imprimé en janvier 1977 par IPV.91700, ch.9, pp.16. 